\title{
The research about psychological determinants of the civil identity formation in adolescence
}

\author{
Yevgeniy Chorniy $^{1^{*}}$, Ann Galchenko ${ }^{2}$ \\ ${ }^{1}$ V.I. Vernadsky Crimean Federal University, 295007 Simferopol, Russia \\ ${ }^{2}$ Crimean Republic Crimean Republic In-service Teaching Training Institute, 29500 \\ Simferopol, Russia
}

\begin{abstract}
The article presents the theoretical model of the study of civil identity. The model of the civil identity research is presented as the ratio of two indicators: the status of civil identity and the content of its structural components (cognitive, emotional-evaluative, need-motivational). At the cognitive component level the psychological determinant of the civil identity formation is determined as the ability to conceptualization in the field of civil problems; at the emotional-evaluative level - the combination features of positive / negative civil identity valence and the personality reflexivity level; at the emotional-evaluative component level - the nature structural organization of the adolescents' civic activity motivation. As the result of the empirical research it is revealed that the process of the status of civil identity formation is due to the selected psychological determinants and is characterized by the following regularities: the transition from lower statuses (diffuse and predefined) to higher (moratorium and reached) is accompanied by the progressive change of the development of the ability to conceptualize, the changes in the motives of the structural connections content and the young people's civil activity motivation structure differentiation, and the differences in the priority type of emotionalevaluative attitude to civic identity.
\end{abstract}

\section{Introduction}

One of the key characteristics of modern Russian society is its transitivity - the multiplicity and dynamics of changes while preserving the significant number of previous values, forms and models of relations [1]. This became agent for uncertainty of civil norms, ideals, identification samples and, as a result, is reflected in the consciousness of people by cognitive ambiguity, conflict of identities, disorientation in the system of social values and their contradictory relationship with personal meanings.

The pedagogical community has the special role in creating the educational environment which conducive to the development of the conscious civic identity of the young generation. With that, the analysis of pedagogical practices on the problems of

*Corresponding author: cherney56@mail.ru 
formation of civil identity of the youth indicates that the scientific potential of psychological knowledge is not used sufficiently, there is still a need to develop technologies, program-didactic and methodological tools that take into account the mechanisms of transition from the impersonal knowledge at the level of values, personal meanings and values in relation to civil society. The creation of theoretical models for the research of civil identity is important from the point of view of the effectiveness of work in this direction. As well as the definition of psychological determinants of the formation of civil identity, which can be the basis of the theory and methodology of civic education.

The aim of the work is research the psychological determinants that determine the process of formation of civil identity in adolescence.

\section{Literature review}

Theoretical grounds of the phenomenon of civic identity in Russian psychology is developed in the scientific works of A. G. Asmolov, M. S. Guselceva, O. A. Karabanova, N. V. Bezgina, N. L. Ivanova, G. B. Mazilova $\left[\begin{array}{lll}2, & 3, & 4\end{array}\right]$ N. M. Lebedeva and T. G. Stefanenko's researches made the significant contribution to the expansion of the laws' understanding of civil and ethnic identity and it's interconnexion [5, 6]. In this context also worked M. V. Drobovtseva, V. M. Kotova, K. V. Zlokazov, N. I. Leonov, A. A. Fomin, A. I. Simanina [7, 8, 9]. T. V. Evgenyeva, V. V. Regnatskiy, O. I. Efremova, O. V. Rozhkova have series of studies which are aimed at research of bases for self-identity and perceptions, reflecting the system of beliefs and values, which belong to the civil (national) identity [10,11, 12]. The scientific work of O. I. Efremova, A. V. Rozhkova, T. V. Anisimova, P. A. Bychkov, O. A. Koryakovtseva, T. V. Bohaichuk and others are carried out to research the profile of role positions of civil identity $[11,12,13,14]$. The large study of the development level of civil identity in the regions of the Russian Federation is presented in the monograph by L. A. Stepnova [15].

The number of researches by E. Finell, K. Liebkind, M. Kemmelmeier and D. Winter are devoted to the identification and explanation of the factors influencing on the national identity $[16,17]$. In the scientific works of J. Meeus, B. Duriez, N. Vanbeselaere and

F. Boen are studied the relationship between intragroup identification and national prejudices [18].

The article proposes the theoretical model of the civil identity's study. The study of civic identity as the psychological phenomenon presented in two dimensions: vertical and horizontal. The vertical plane engage the establishment of identity status (on the basis of the status theory of ego-identity J. Marcia [19]), horizontal - the research of the content of the structural organization of each of the statuses (cognitive, emotional-evaluative, needmotivational components). The basis of the level organization of civil identity with the cognitive component has based on the criterion of the ability to conceptualize in the field of civil issues; with the emotional and evaluative component - features of the combination of positive / negative valence of civil identity and level of reflexivity of the personality; due to the need-motivational component - the nature of the structural organization and motivation of the civil activity.

\section{Materials and methods}

The research program included four stages. 
The objective of the first phase - determination adolescents' civil identity status using a questionnaire of 24 statements. Four samples were formed according to the results of the survey: the respondents with diffuse, predefined, achieved status of civil identity and adolescents in the state of moratorium.

The objective of the second phase - the diagnosis of the level of ability's development to conceptualization in the field of civil problems which have teenagers with different status of civil identity. The content analysis of the texts was carried out to determine the level of development of the ability to conceptualize; it was recorded in a structured conversation with high school students. On the basis of the theory of conceptual thinking by

M. A. Kholodnaya were singled out the criteria of the text analysis: the formal answer with factual type; the statements of the argumentative type; the statements of the systematizing type; the interpretations, including varying and alternative (generalization, result); the implicit signs of the listed facts which were revealed by the respondent; the identification of the cause-and-effect relationships.

The objective of the third phase - the definition of the motivation structure features of civil activity in adolescents with different status of civil identity. The method of identifying the motivational structure of teenager's socially useful activity developed by O. V. Lishin on the basis of LMT test by V. Hennig, was used for realization of the task. During the phase of processing and describing the results of the research, the analysis of structural relationships between the motives of socially useful activities was carried out.

The objective of the fourth phase - determining adolescents' priority type of emotionalevaluative attitude to civic identity, taking into account the fact that they have different status of civil identity. These indicators were measured using the scale of rapid assessment of ethnic valence by N. M. Lebedeva (modified version), methods "Types of civil identity" by M. V. Borisov, methods for determining the level of reflexivity by A. V. Karpov,

V. V. Ponomareva. The primary empirical base of the research included 473 students of secondary schools and college of the Republic of Crimea (school № 18, Simferopol; school

№ 34, Simferopol district; "Simferopol economic Lyceum", Simferopol; school № 4, Alushta; "Crimean multidisciplinary College", Simferopol). As the result of determining the status of civil identity in order to research the psychological determinants of the formation of civil identity were formed four different-status samples of 50 people aged 15- 16 years.

\section{Research results}

\subsection{Diagnosis of the adolescents' ability to conceptualize, if they have a different status of civic identity}

The texts obtained in the course of structured interviews were analyzed, and then the points were given, which reflected the level of development of the respondent's ability to conceptualize in the field of civil issues. In this study, we did not use the quantitative method of content analysis, in which the unit of analysis that reflected a certain type of statement was fixed only once in the text (factual type; argumentative type, etc.). Thus, the maximum score of the text was equal to the number of selected criteria - six.

According to the results of evaluating the ability to conceptualize adolescents with different status of civic identity was made comparison by determining statistically significant differences between the scores obtained in different samples and determination of statistically significant differences between the established level of conceptualization 
ability which had adolescents from different-status samples, where 1-2 points was taken as the low level, 3-4 - the average level, 5-6 - the high level). The identification of differences in the samples was established using the nonparametric Kruskal-Wallis test. The value of the criterion was $\mathrm{H}=137.7$, the number of degrees of freedom $\mathrm{k}=3$. The difference at the

level of significance is revealed as $\mathrm{p}<0,001$. Pairwise comparisons of samples were carried out using Dunn's Criterion Value.

Multiple comparisons of the development level of the ability to conceptualize in difference samples were carried out using the Chi-square test. Bilateral critical area. The variables accept 3 levels of values. Chi-square $=157,10$, the number of the freedom degrees $\mathrm{k}=6$. The difference is statistically significant at the level $\mathrm{p}<0,001$.

It can be concluded that in the process of formation of civil identity the transition from the lower status of identity (predefined) to the higher status (moratorium and reached) is accompanied by the progressive change in the level of development of the ability to conceptualization. Young people who have been given the status of civil identity have features of structuring data in the field of civil issues. Mainly it has factual and argumentative character. The organization of individual experience is limited by the perception and understanding of civic reality in the context of available information. Teenagers at the level of achieved civic identity or in the state of active search are ready for productive transformation of factual data and their interpretation. The diffuse status of civil identity is mainly characterized by the low level of development of the ability to conceptualize in the field of civil problems (78 \%). However, it is impossible to ignore the $22 \%$ of teenagers who have an average level of ability to conceptualize.

\subsection{Diagnosis of teenagers' motivational structure of civic activity if they have different status of civic identity}

Based on the diagnostic data (according to the method of $\mathrm{O}$. V. Lishin) is compiled matrix correlation for the four difference-status samples (the significant correlations are revealed at $\mathrm{p}<, 05000)$.

According to the results of the analysis, it is concluded that there are a number of key trends:

- $\quad$ in the process of civil identity formation in the transition from lower statuses (diffuse and predefined) to higher (moratorium and reached) there is the tendency to reduce the correlation between the individual type motives. These changes indicate that the integration between the motives of the first type has decreased and, therefore, the activity decreases in the mechanism of regulation of civil behavior. It should also be noted the distinction in the samples of different status on the correlations content between the individual type motives. One of these differences in the structure of the teenagers motivational sphere in the status of moratorium is the loss of all significant links with the motive of the coercion acceptability to socially useful activity and the links formation with the motive of self-affirmation. At the achieved civic identity level, there are no significant links, both with the motive of acceptability coercion, and with the motive of pragmatic benefits;

- the correlations between group motives who have teenagers with different status of civil identity reflect the dynamic changes in the perception of high school students of social environment as part of civil society, and its importance in the formation civil behavior motivation. There is reason to assume that the changes occur in the following direction: the diffuse status - the teacher and family members are "single social entity", which regulates the implementation of socially useful activities (the significant correlation between the motive of social identification with the teacher and the motive of 
social identification with the family is found); the predefined status - there is the selection of individual personality- significant adults, the manifestation of civil activity is focused on their evaluation (the absence of significant links between the motives of identification with the teacher, parent and peers); moratorium - the teachers and parents, as bearers of civic values, are "depersonalized", and their value is leveled; and finally, teenagers with the achieved status

of civil identity have fundamentally different characteristics of the correlation structure of group motives;

- $\quad$ in the diffuse civil identity status, social motives do not form significant correlations among themselves and, moreover, have significant correlations with individual motives. Such organization of the motivational sphere may give the other meaning to the teenager's socially useful activity. At the level of achieved civil identity status in the structure of the motivational sphere of teenagers are formed the significant correlation between social motives, then the connections between social motives and motives of other types arelost.

\subsection{Diagnosis of the type adolescents' emotional-evaluative attitude to citizenship, if they have a different status of civic identity}

Two variables were identified as the type-forming indicators: the valence of civic identity and the level of reflexivity of personality.

It can be stated that the adolescents' samples with the predetermined and reached status of civil identity are the most homogeneous by the type of emotional-evaluative attitude to citizenship. Both young people with negative and positive civic identity can move to the stage of finding the conscious decision regarding their citizenship. On both occasions, the characteristic feature of the moratorium period is the increased level of the individual's reflexivity. Hypothetically, the diagnostic results of the adolescents with diffuse status of civil identity indicate the several subtypes' of this status. The possible subtypes are similar in the presence / absence identity units term as civic values, experiences, relationships (in the diffuse status - the absence of identity units) and are differ by the presence / absence period of "search for alternatives" criterion. It can be assumed that the adolescents with indifferent and negative civic identity, low levels of reflection and ability to conceptualize in the field of civil issues have not experienced the stage of the understanding their citizenship, awareness of belonging to civil society and finding their place in it. In the sample with diffuse status of civil identity find out another category of adolescents. This category is characterized by indifferent or negative valence of civil identity, but the average indicators of reflection and ability to conceptualize. This combination may indicate that the absence of identity units is the deliberate refusal that has been accepted as the result of reflection. Still the debatable question is whether teenagers with the negative civil identity can be referred to the diffuse status, which is characterized by the absence of civil identity units. If we assume that it is impossible, the four statuses do not detect the entire variability of this phenomenon. Based on the provisions of the social identity construction model by

E. V. Chorniy, it is important to take into account that "stadiality" is only one of the facets of the social identity multidimensional phenomenon study (including civil). There is the number of other essential characteristics (constancy, valence, hierarchy, sociality, homogeneity, transformation, fluctuation). It can be used as the matrix for filling it with different content depending on the subject of research - the type of identity and goals [20]. 


\section{Discussion and conclusions}

In the research, the status of civic identity, reflecting the characteristics of awareness and experiencing one's belonging to the society and the state, is presented and studied as the structure that includes cognitive, emotional-evaluative and need-motivational components. Transition from lower civic identity statuses (diffuse and predefined) to higher (moratorium and reached) is characterized by:

- The development level of the ability to conceptualize has progressive change;

- $\quad$ The change in the content of motives' structural bonds and motivation of civic activity structure differentiation from diffuse integrity to system differentiation;

- The priority type of emotional-evaluative attitude of the individual is changed to civic identity.

Thus, as the result of empirical research, it have been proved that the process of formation of the civic identity status is due to a number of psychological determinants. Consequently, it can be assumed that the effectiveness of the formation of civic identity is associated with focused psychological and pedagogical work at the cognitive level - with the development of the ability to conceptualize in the field of civilian issues (the establishment of implicit signs, relationships and patterns, interpretation and forecasting); at the need-motivational level - with the identification of priority motives, conflicts of motives, the updating of prosocial motives; at the emotional value level - with the formation of the civic identity positive valence through the reflection of personally significant aspects of civil life.

The reported study was funded by RFBR and EISR according to the research project № 19-01131507

\section{References}

1. D. Andreyeva, Scientific dialogue, 4, 292 (2018)

2. Asmolov A. G., Karabanova O. A., Guselceva M. S. et al., Formation of civil identity as a key task of education and social and cultural modernization of Russia (FIRO Publ, Moscow, 2012)

3. N. V. Bezgina, News Of Tulgu. Humanities, 3-1, 241 (2013)

4. N. L. Ivanova, G. B. Mazilova, News of Saratov University. New series. Acmeology of education. Developmental psychology, 4, 11 (2010)

5. N. M. Lebedeva, Introduction to ethnic and cross-cultural psychology (Staryj sad Publ, Moscow, 1999)

6. T. G. Stefanenko, Social and psychological aspects of the research of ethnic identity (Staryj sad Publ, Moscow, 1999)

7. M. V. Drobovtseva, M. V. Kotova, Psychological research, 9 (47), 1 (2016). (In Russ.)

8. K. V. Zlokazov, N. I. Leonov, Russian psychological journal, 3, 197 (2016)

9. A. A. Fomin, A. I. Simanina, Actual problems of psychological knowledge, 3 (36), $123(2015)$

10. T. V. Evgenieva, V. V. Regnatsky, Values and meanings, 2(36), 5 (2015)

11. O. I. Efremova, Concept, 04, 1 (2015)

12. A. Rozhkova, Bulletin of BSU, 1 (2), 164 (2012)

13. T. V. Anisimova, P. A. Bychkov, Vestnik St. Petersburg University. Series 16 : Psychology. Pedagogy, 3, 63 (2015)

14. O. A. Koryakovtseva, T. V. Bugaichuk, Yaroslavl pedagogical Bulletin, 4, 143 (2013)

15. L. A. Stepnova, A. A. Derkach, E. V. Selezneva et al., The Development of civic 
identity in the multicultural environment of the Russian society (Narodnoe obrazovanie Publ, Moscow, 2017)

16. E. Finell, K. Liebkind, British J. of Social Psychology, 2(49), 321(2010)

17. M. Kemmelmeier, D.G. Winter, Political Psychology, 6(29), 859(2008)

18. J. Meeus, B. Duriez, N. Vanbeselaere, F. Boen, British J. of social psychology, 49, 305 (2010)

19. J. E. Marcia, Identity: An International J. of Theory and Research, 2(1), 7(2002)

20. Y. Chorniy, Political Space and social time: identity and everyday life in the structure of living space, 48-54 (2018) 